
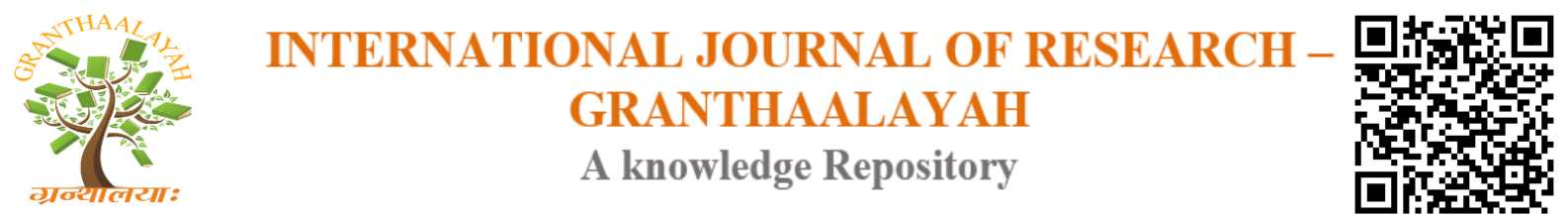

Social

\title{
FLIP TEACHING IN PROMOTING ACTIVE STUDENT LEARNING
}

\author{
Ligi B ${ }^{1}$, Dr. B. William Dharma Raja ${ }^{2}$ \\ ${ }^{1}$ Ph.D Scholar, Manonmaniam Sundaranar University, Tirunelveli- 627 012, INDIA \\ ${ }^{2}$ Head I/C, Department of Education, Manonmaniam Sundaranar University, Tirunelveli- \\ 627 012, INDIA
}

DOI: https://doi.org/10.29121/granthaalayah.v4.i8(SE).2016.2585

\begin{abstract}
During the past decade, the teachers in the schools have increased their use of Internet based content and resources in their classrooms. This paper briefly explains about a new teaching method known as flip teaching (FT) where students can adjust some features according to their preferences and learning style, which also supports to educate the children in a active learning $(A L)$ environment. The system is capable of assisting children which can make them engage in learning activities successfully. This environment enables monitoring students' progress, total time students have spent in the system, their activity on the class, the overall achievements in lessons learned, tests performed and solutions to given projects which helps in active student learning. Personalized assistance that teacher provides in a traditional classroom is not easy to implement. FT is booming as the education becomes more demandfocused. Also, this method suggests ways to bridge the gaps between students and instructors and students and their peers, which are typical of online learning and face-to-face learning.
\end{abstract}

Keywords:

Flip Teaching (FT), Online learning, Active Learning (AL).

Cite This Article: Ligi B, and Dr. B. William Dharma Raja, "FLIP TEACHING IN PROMOTING ACTIVE STUDENT LEARNING", International Journal of Research Granthaalayah, Vol. 4, No. 8: SE (2016): 40-44.

\section{INTRODUCTION}

FT refers to the reverse teaching method in which the students first study the topic by themselves using the lessons prepared by the teacher through online and do the homework in the classroom by discussing with their peers and the teachers. The flipped classroom employs asynchronous video lectures and practice problems as homework, and active, group-based problem solving activities in the classroom (Bishop \& Verleger, 2013). In flipped classrooms students learn by themselves at their own pace. Students can also help each other, a process that benefits both the advanced and less advanced learners. FT is an approach that benefits students by providing 
multiple pathways to gain knowledge, understanding and also new learning opportunities start to emerge.

Concepts and ideas, which cannot easily be represented in words or even through illustrations, can be easily created and viewed from different angles using computer animations. Animation captures attention, and the information which is presented as a moving image is retained by the students for a longer time and with great accuracy. The use of images, along with words, diminishes the overwhelming nature of text and helps the student to manage the cognitive load, which increases retention. FT helps the students to learn by their own pace. The students will be interested in watching the video lectures before the topic is taught in the school. They are able to watch the videos as many times they want. It also creates interest in students to solve the problems and home works with their peers.

In FT, the video lectures are more effective at delivering the course content than the textbook, which is still used as a resource. It helps the teachers to monitor the extent to which students are doing the assigned work in and out of the classroom. Flipping have seen higher student achievement, increased student engagement, and better attitudes towards learning and school (Finkel, 2012).

When students receive the lecture outside of class, they can use time in class with their peers more effectively by breaking up into smaller discussion groups or engage in other in-class activities. Teachers can also make more effective use of their time by reviewing content that students actually need help with and guiding the students. The flipped learning model also allows for students in classes of all sizes. Flipped learning helps students to take more responsibility for their own learning. Working in class along with the peers and the guidance of teachers, the students learn to think more critically, communicate more effectively, which increases their reading comprehension. In a flipped classroom, students can improve both learning and engagement (Aaronson \& Intern, 2013).

\section{CHARACTERISTICS OF A FLIPPED CLASSROOM}

According to Bruder (2012), a flipped class is not just videos instead of live instruction. FT when done correctly the classroom structure, student responsibility, interaction between the teacher and students and student engagement will promote active student learning. The characteristics of a flipped classroom are: Student-led discussions, tutoring and collaborative learning, critical thinking, problem-based learning, student ownership, student exploration, student engagement and transformative learning.

\section{KEY ELEMENTS OF FLIP TEACHING}

FT provides various opportunities for the teachers and students for active learning. Some of the key elements of FT are:

1) An opportunity for students to gain first exposure prior to class. FT provides an opportunity for the students to view the lessons before the class. The videos can be created by the instructor or found online from YouTube or other similar sources. 
2) An incentive for students to prepare for class. Students completed a task associated with their preparation and that task was associated with points. The assignment can vary from online quizzes to worksheets to short writing assignments. This helps the students to create their own problem solving skills, developing new games, puzzles etc.,

3) A mechanism to assess student understanding. The pre-class assignments that students complete as evidence of their preparation can also help both the instructor and the student assess understanding. Pre-class online quizzes can allow the instructor to practice Just-inTime Teaching (JiTT; Novak et al., 1999), which means that the instructor can focus on the elements with which students are struggling. If automatically graded, the quizzes can also help students pinpoint areas where they need help. Pre-class worksheets can also help focus student attention on areas with which they're struggling. Pre-class writing assignments help students clarify their thinking about a subject, thereby producing richer in-class discussions. Much of the feedback students need is provided in class, reducing the need for instructors to provide extensive commentary outside of class (Walvoord \& Anderson, 1998).

4) In-class activities focus on higher level cognitive activities. If the students gained basic knowledge outside of class, then they need to spend class time to promote deeper learning. The activity will depend on the learning goals of the class and the culture of the discipline. Students may spend time in class engaged in debates, data analysis, or synthesis activities. The students use their class time to deepen their understanding and increase their skills at using their new knowledge.

\section{ACTIVE LEARNING}

Active Learning (AL) involves students in doing things and (have the students) think about the things they are doing. AL means engage the students with materials participate in the class and make them to have discussions and collaborate with each other. Students learn more when they participate in the process of learning, whether it is through discussion, practice, review or application (Grunert, 1997). AL facilitates independent, critical and creative thinking. It helps students to analyze, synthesize, gets involve in group discussions etc. When students are given opportunities to actively participate in learning environment, they take more responsibility for their performance in the class. And also when they have opportunity to make discussions about what they learn and how they use that knowledge, students see a course as more valuable and more directly related to their goals. FT involves students in classroom activities which requires them to assess to understand their skill and forces them to develop a deeper understanding of the given topic.

\section{COMPONENTS OF ACTIVE STUDENT LEARNING}

The various components of Active Student Learning are:

1) Student Centered. An active learning classroom is largely student-centered. This means shifting the focus from the teacher to the student. In this environment it's the students who decide what they learn, how they'll do it, and how they'll assess it. The teacher is a facilitator of learning. As a "guide on the side" they encourage the students and develop critical thinking skill.

2) Highly collaborative. Students love to do their work together. Any chance to learn by collaborating is something students take to with lots of enthusiasm. That's why an active 
learning classroom is built on collaboration and teamwork. When students collaborate, they're working on more than just content-based projects.

3) Students own their learning. The classroom is student-focused. A teacher can't and shouldn't do everything for the student. The responsibility of the teachers is to teach the students to learn from mistakes. When students learn that mistakes can be positive experiences they learn not to fear failure, and see it as merely part of the journey to success.

\section{FLIP TEACHING - BENEFITS}

Because flip teaching brings together the best of technology-based online learning and face-to-face instruction, students have access to a focused program of courses delivered in multiple modalities to keep them connected, teachers have a dynamic environment in which to deliver the instruction in real time through robust technology platforms, and all participants finally enjoy real anytime, anywhere learning.

- A continuum of options for each student: Flip programs can include both full-time and supplementary offerings. Districts are finding it useful to embrace a portfolio approach to online learning opportunity. This fulfills the need for the kind of universal access to online learning long promoted by organizations like iNACOL, the International Association for K12 Online Learning.

- Strategic roles for all teachers: In practice, flipped learning programs often develop complementary roles for the in-person and online teachers. In cases where those roles are defined and coordinated, outcomes have been positively impacted. The face-to-face teachers' energetic commitment to "the whole student," is enhanced by the data-driven collaboration with their online, subject-focused counterparts. FT meets various aspects of teacher best practice can be distributed and scaled to maximize student achievement.

- True anytime/anywhere learning: Flipped learning helps the students learn at anytime, anywhere such as in labs, at home, in the community, and at their base schools and also mobile access as well. Flipped learning should focus less on the either/or combination of face-to-face and online and more on the vision of learning flipped into all aspects of our lives (Pearson, 2012).

FT provides active learning for all the students in the classroom and effective in engaging learners and assisting them in creating their own learning experiences. FT develops new activities to engage learners in the online environment. FT provides active learning strategies and methods to enhance learning and support the learning objectives. When FT is done in right way, it is more effective, and learning challenges takes place. FT if carried out properly it helps in promoting active student learning which allows them to reach their full potential. A flipped classroom allows students to learn on their own time, at their own pace and they have more time for collaborating with other students which can be a great learning experience for the students which provides way for them to build their teamwork abilities. The students can replay the video lectures as many time they want to learn. When used appropriately, FT allows students to recall information, answer questions posed by the teachers, creates meanings, generalize and summarize text contents. It is an effective teaching technique for active student learning and also creates interest in their learning. 


\section{RECOMMENDATIONS}

Teachers may find challenges with this FT method with increased preparation time, technical knowledge and creating high quality videos. The institutions may provide additional funding to secure training for teachers to develop multimedia packages involved in the successful implementation for this method. Teachers should put effort to create their own multimedia packages for their subjects for successful implementation. Giving training courses to all subject teachers regarding the use of multimedia in teaching educational subjects. The institution may improve teacher's capacity to develop the more sophisticated courses. i.e., Teachers need time, resources and support to develop both their skills and their courses. Workshops may be given to teachers the opportunity to explore learning technology. Teachers should redesign their courses for flipped teaching, not just by adding an online content to their regular teaching.

\section{REFERENCES}

[1] Anderson, L.W., \& Krathwohl, D. (2001). A taxonomy for learning, teaching, and assessing: revision of Bloom's taxonomy of educational objectives. New York: Longman.

[2] Aronson N., \& Intern P. (2013). Flipped Learning in Higher Education. Retrieved from http://www.flippedlearning.org/cms/877.637.1604

[3] Berrett, D. (2012). How 'flipping' the classroom can improve the traditional lecture. The Chronicle of Higher Education.

[4] Bishop, J. L., \& Verleger, M. A. (2013). The flipped classroom: A survey of the research. American society for engineering education. ID 6291

[5] Bruder, P. (2012). The flipped classroom reversing the way we teach. Retrieved from http://www.njea.org/news-and-publications/njea-review/february-2012/the-flippedclassroom-reversing-the-way-we-teach.

[6] Golden, S. A. R. (2011). Problems and Prospectus of Distance Learning. Bharathidhasan University, 343, 344.

[7] Golden, S. A. R. (2011). Strategy For Success Of Human Beings:-Time Management.

[8] Grunert, Judith. The course syllabus: A learning-centered approach. Bolton, MA: Anker Publishing Co, Inc, 1997.

[9] Finkel Ed. (2012). Flipping the script in K12. Retrieved from http://eric.ed.gov/?id=EJ984780/. ISSN-1537-5749

[10] Flipped Classroom work. Retrieved from http://www.universitybusiness.com/article/5reasons-flipped-classrooms-work.

[11] Regi, S. B., \& Golden, S. A. R. (2014). A Study On Educational Loan Availed By Students In Trichy City. JOURNAL OF INTERNATIONAL ACADEMIC RESEARCH FOR MULTIDISCIPLINARY (JIARM), 2(1).

[12] Novak, G., Patterson, E.T., Gavrin, A.D., \& Christian, W. (1999). Just-in-Time Teaching: Blending Active Learning with Web Technology. Upper Saddle River, NJ: Prentice Hall.

[13] Pearson, (2012). Blended Learning: How Brick-and-Mortar Schools are Taking Advantage of Online Learning Options. Retrieved from

http://www.connectionslearning.com/Libraries/Institutional_Sales/Blended_Learning_ Primer_FINAL_l.pdf

[14] Walvoord, B.E., \& Anderson, V.J. (1998). Effective grading: A tool for learning and assessment. San Francisco: Jossey-Bass. 